\title{
Review Article \\ Regulation of T Helper 17 by Bacteria: An Approach for the Treatment of Hepatocellular Carcinoma
}

\author{
Cecilia Ying Ju Sung, ${ }^{1}$ Nikki Pui-yue Lee, ${ }^{2}$ and Hani El-Nezami1 \\ ${ }^{1}$ School of Biological Sciences, Faculty of Sciences, Kadoorie Biological Sciences Building, The University of Hong Kong, \\ Pokfulam, Hong Kong \\ ${ }^{2}$ Department of Surgery, LKS Faculty of Medicine, The University of Hong Kong, Pokfulam, Hong Kong
}

Correspondence should be addressed to Hani El-Nezami, elnezami@hku.hk

Received 1 August 2012; Accepted 26 November 2012

Academic Editor: Weiliang Xia

Copyright (C) 2012 Cecilia Ying Ju Sung et al. This is an open access article distributed under the Creative Commons Attribution License, which permits unrestricted use, distribution, and reproduction in any medium, provided the original work is properly cited.

T helper 17 ( $\left.\mathrm{T}_{\mathrm{H}} 17\right)$ is a novel subset of $\mathrm{T}$ helper cells that has recently been identified in the hepatocellular carcinoma (HCC) tumor environment. Its presence seems to be linked with HCC progression, possibly via facilitating angiogenesis. The origin of tumorassociated $\mathrm{T}_{\mathrm{H}} 17$ may be related to the gut, in which the differentiation of $\mathrm{T}$ cells, especially $\mathrm{T}_{\mathrm{H}} 17$ cells, is affected by microbiota. As $\mathrm{T}_{\mathrm{H}} 17$ may appear to be a new therapeutic target against tumor-promoting inflammation, strategies such as using probiotics to polarize the response away from $\mathrm{T}_{\mathrm{H}} 17$ may be beneficial to slow down tumor progression. This paper will attempt to discuss the potential linkage between HCC progression, $\mathrm{T}_{\mathrm{H}} 17$, and gut microbiota and the possible therapeutic implications of probiotics to modulate $\mathrm{T}_{\mathrm{H}} 17$-mediated response for tumor growth.

\section{Introduction}

Hepatocellular carcinoma (HCC) is the fifth most common cancer worldwide and is characterized by poor prognosis [1]. Tumor progression has now been recognized as the product of crosstalk between cancer cells and stromal cells, including immune cells [2]. Immune status appears to be different in distinct sites of the tumor [3]. The intratumoral region is generally in an immunosuppressive state [3] it contains dysfunctional antigen presenting cells, altered proportion of effector to regulatory $\mathrm{T}$ cells, and an abundance of immunosuppressive molecules, forming a network to facilitate immune evasion [4]. In contrast, the peritumoral stroma is highly infiltrated with various immune cells that actively secrete high concentrations of inflammatory cytokines for enhancing cell growth, angiogenesis, and tissue remodelling [3]. Hence, inflammatory response has been suggested to be rerouted in a tumor-promoting direction. Recently, $\mathrm{T}_{\mathrm{H}} 17$ cells have come into research focus as they have been identified in a number of tumors including HCC. $\mathrm{T}_{\mathrm{H}} 17$, and its effector molecules interleukin-17 (IL-17) and IL-22, are potent inducers of tissue inflammation and have been associated with a number of inflammatory and autoimmune diseases $[5,6]$. The role of $\mathrm{T}_{\mathrm{H}} 17$ is paradoxical, but now there is accumulating evidence to illustrate that $\mathrm{T}_{\mathrm{H}} 17$ has tumor promoting effects in some cancer such as HCC. Though the origin of tumor associated $\mathrm{T}_{\mathrm{H}} 17$ cells is not completely understood, it is possible that they are recruited from the periphery [7]. The gut is the natural site of $\mathrm{T}_{\mathrm{H}} 17$ generation and it has recently been found that microbes can affect $\mathrm{T}$ cell differentiation via regulating dendritic cells. Thus, there appears to be a complex relationship between HCC progression, $\mathrm{T}_{\mathrm{H}} 17$ and gut microbiota. In this paper, the potential linkage between these three factors and the possible therapeutic implications of probiotics to modulate $\mathrm{T}_{\mathrm{H}} 17$ mediated response for tumor growth will be discussed.

\section{Relationship between IL-17-Producing Cells and HCC Progression}

IL-17 is a proinflammatory cytokine produced primarily by a novel subset of CD4+T cells known as $\mathrm{T}_{\mathrm{H}} 17$. In addition to $\mathrm{T}_{\mathrm{H}}$ cells, this cytokine can also be secreted by CD8+T 
cells, $\gamma \delta \mathrm{T}$ cells, lymphoid tissue inducer (LTi) cells, natural killer (NK) cells, and granulocytes [8]. At present, the IL17-producing cells in human HCC tissue are found to be from the adaptive arm of immunity. A majority of them were identified to be $\mathrm{T}_{\mathrm{H}} 17$, though a substantial amount of IL$17+\mathrm{CD} 8+\mathrm{T}$ cells can also be found in tumor. In addition to IL-17, these cells may also secrete IL-22, which was recently found to be related to HCC as well, though its production is not limited to $\mathrm{T}$ cells [9-11].

The role of $\mathrm{T}_{\mathrm{H}} 17$ cells in tumor immunity has been controversial. However, several lines of evidence suggested that these cells play a protumor role in HCC. Increased levels of $\mathrm{T}_{\mathrm{H}} 17$ cells were found in tumor tissue [12] and in peripheral blood [13] of HCC patients, and their level is correlated with unfavorable disease outcomes $[7,12,14]$. Similar results have also been observed in animal models, whereby limiting tumor $\mathrm{T}_{\mathrm{H}} 17$ expansion reduced the growth of transplanted liver tumor in rodents [7].

Many functions of IL-17 in the tumor microenvironment contribute to tumor progression. Apart from a minor direct effect on the proliferation and survival of cancer cells in other systems [15], and the recent report on its role in immune evasion via mediating B7-H1 expression on monocytes to suppress cytotoxic $\mathrm{T}$ cell activity [13], the major protumor role of IL-17 in inflammation-associated cancer relies on fostering angiogenesis. Indeed, both animal and human HCC tissues revealed that their levels were positively correlated with microvessel density and that these cells were observed to be enriched predominately at the invading edge of tumor tissue, the site where angiogenesis is most active [12]. The proangiogenic effect of IL-17 could be linked to its interaction with various stromal cells such as fibroblasts, keratinocytes, epithelial and endothelial cells. IL-17 leads to the induction of IL-6, IL-8, prostaglandin (PG) $\mathrm{E}_{1}$, and PGE 2 as well as enhancement of intercellular adhesion molecule-1 expression [16-19]. IL-17 also participates in mobilization and recruitment of neutrophils [20] as well as inducing the secretion of tumor necrosis factor- $\alpha$ (TNF- $\alpha$ ) and IL- $1 \beta$ from macrophages [21]. The collective effect results in the release of an array of proangiogenic cytokines including vascular endothelial growth factor (VEGF), hepatocyte growth factor and keratinocyte-derived chemokine in the tumor microenvironment [22]. Thus, IL-17 inevitably shifts the local biologic balance toward a predominance of angiogenic factors to enhance the net angiogenic activity. Owing to the highly vascular nature of HCC, IL-17+ cells may play an important role in progression of this type of tumor.

In addition to IL-17, it is conceivable that $\mathrm{T}_{\mathrm{H}} 17$ cell promote HCC via IL-22 production as well. Though there were only a few reports on the role of IL-22 in tumors, the literature generally supported the tumor-promoting function of this cytokine. A recent report from Jiang et al. [10] illustrated the excessive expression of IL-22 in HCC microenvironment and its expression appears to be related to advanced cancer stages. Conversely, knockdown of IL22 inhibited tumor progression in a xenograft model of other systems [23]. The tumor promoting effect of IL-22 is believed to be mediated by signal transducer and activator of transcription factor 3 (STAT3), an oncogenic transcription factor constitutively activated in various malignancies [24]. In human liver cancer cells, IL-22-induced STAT3 activation promoted at least three hallmarks of cancer (proliferation, survival and angiogenesis) via the upregulation of a variety of mitogenic (cyclin D1, c-myc, and Rb2), anti-apoptotic (Bcl2 and $\mathrm{Bcl}-\mathrm{xL})[10,25]$, and angiogenic (VEGF) [10] genes. IL-22 was also shown to have immunosuppressive functions in other cancer [26], though it was not well studied in HCC so far.

Since $T_{H} 17$ cells may act to promote HCC pathogenesis via production of IL-17 and IL-22; if we can modulate the $\mathrm{T}_{\mathrm{H}} 17$ status in the body, it may be possible to affect tumor progression. In order to do this, we first need to know the origin of tumor-associated $\mathrm{T}_{\mathrm{H}} 17$ cells.

\section{Potential Source of Tumor-Associated $\mathbf{T}_{\mathbf{H}}-17$ Cells}

Tumor-associated $\mathrm{T}_{\mathrm{H}} 17$ cells may either be induced in the tumor microenvironment and/or recruited from distal sites.

In situ induction occurs when memory $\mathrm{T}$ cells enter a site of inflammation and encounter activated antigenpresenting cells (APC). Though it has been suggested that tumor-associated-macrophage (TAM) may be responsible for $\mathrm{T}_{\mathrm{H}} 17$ development because it outnumbers dendritic cells (DC), the most efficient APC, in the tumor environment, it appears that tumor-activated monocytes, but not TAM may play a dominant role in $\mathrm{T}_{\mathrm{H}} 17$ expansion in the context of HCC. Kuang et al. [7] have shown that monocytes could be activated by liver cancer cells to secrete several cytokines including IL- $1 \beta$, IL- 6 , IL-23, thereby creating a proinflammatory cytokine milieu that facilitates the in vitro expansion of memory $\mathrm{T}$ cells. While studies in other systems have also demonstrated a critical role of transforming growth factor- $\beta$ (TGF- $\beta$ ) in the development of human $\mathrm{T}_{\mathrm{H}} 17$ [27, 28 ], Kuang and his colleagues failed to find a correlation between the expression of this cytokine and $\mathrm{T}_{\mathrm{H}} 17$ cell density, implicating that the role of TGF- $\beta$ in expanding $\mathrm{T}_{\mathrm{H}} 17$ cells remains to be elucidated in the local tumor environment of HCC. It is interesting to note that $\mathrm{T}_{\mathrm{H}} 17$ cells generated in this cytokine milieu can also produce interferon- $\gamma$ (IFN- $\gamma$ ), which is the signature cytokine of $\mathrm{T}_{\mathrm{H}} 1$ cells. Thus there are two subsets of $\mathrm{T}_{\mathrm{H}}$ cells in HCC tissue: $\mathrm{T}_{\mathrm{H}} 17$ (IL-17+ IFN$\gamma-)$ and $\mathrm{T}_{\mathrm{H}} 17 / \mathrm{T}_{\mathrm{H}} 1$ (IL-17+ IFN- $\gamma+$ ). How $\mathrm{T}_{\mathrm{H}} 17 / \mathrm{T}_{\mathrm{H}} 1$ cells are generated is not yet known but it is possible that the tumor environment induces this phenotype, as most of the circulating $\mathrm{T}_{\mathrm{H}} 17$ cells in HCC patients did not express IFN$\gamma$. IFN- $\gamma$ from $\mathrm{T}_{\mathrm{H}} 17 / \mathrm{T}_{\mathrm{H}} 1$ is suggested to promote further recruitment of $\mathrm{T}_{\mathrm{H}} 17$ by inducing CCL20 expression. CCL20 is the ligand for CCR6, which is a receptor highly expressed in the majority of $\mathrm{T}_{\mathrm{H}} 17$ cells $[7,29]$. A positive feedback cycle may be formed in the tissue environment: CCR6+ memory $\mathrm{T}_{\mathrm{H}} 17$ is homed to tumor site by high levels of CCL20 [12]. It is then converted to $T_{H} 17 / T_{H} 1$, which releases IFN- $\gamma$ to recruit more CCR6+ memory $\mathrm{T}_{\mathrm{H}} 17$ from the periphery pool by the virtue of CCL20.

So where would the potential source for $\mathrm{T}_{\mathrm{H}} 17$ cells be? $\mathrm{T}_{\mathrm{H}} 17$ cells are preferentially enriched in the intestinal lamina 


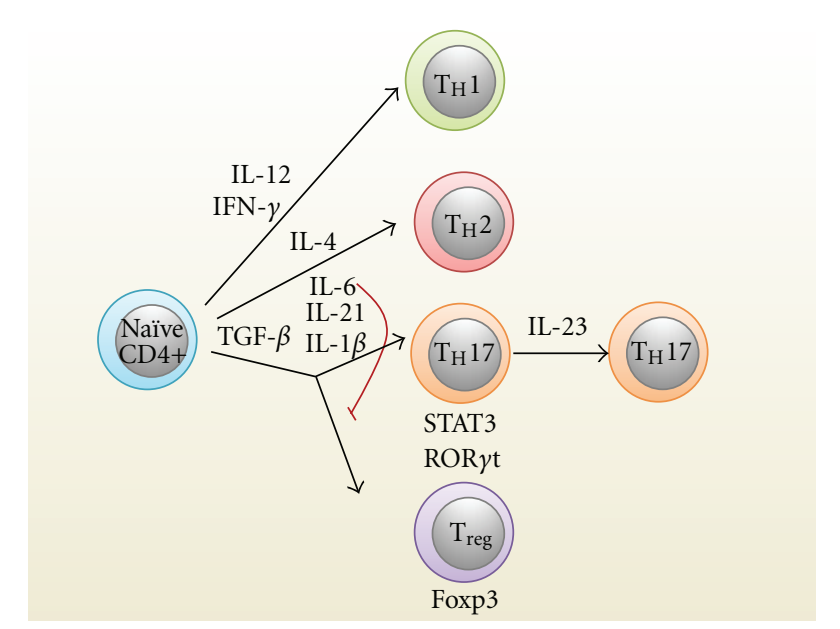

Figure 1: Polarization of $\mathrm{T}$ helper $\left(\mathrm{T}_{\mathrm{H}}\right)$ cell subsets. Naïve CD4+ $\mathrm{T}$ cells develop into different lineages $\left(\mathrm{T}_{\mathrm{H}} 1, \mathrm{~T}_{\mathrm{H}} 2, \mathrm{~T}_{\mathrm{H}} 17\right.$, and $\left.\mathrm{T}_{\text {reg }}\right)$ in response to cytokine cues produced from antigen presenting cells. IL: interleukin; interferon $\gamma$ : IFN- $\gamma$; FOXP3: forkhead box P3; ROR $\gamma$ t: retinoic acid-related orphan receptor $\gamma$ t; STAT: signal transducer and activator of transcription; $\beta$ : TGF- $\beta$ transforming growth factor.

propria of ileum and colon, while very low frequencies of these cells are present in extraintestinal sites at a steady state [30-32]. Polarization of naïve T cells is influenced by diverse signals produced by APC to develop into distinct effector $\left(\mathrm{T}_{\mathrm{H}} 1, \mathrm{~T}_{\mathrm{H}} 2\right.$, and $\left.\mathrm{T}_{\mathrm{H}} 17\right)$ or regulatory $\left(\mathrm{T}_{\text {reg }}\right)$ lineages (Figure 1). It is now recognized that IL-12 and IFN- $\gamma$ are needed for $\mathrm{T}_{\mathrm{H}} 1$ induction, whereas $\mathrm{T}_{\mathrm{H}} 2$ differentiation requires IL-4, and $\mathrm{T}_{\text {reg }}$ requires TGF- $\beta$ [33]. For $\mathrm{T}_{\mathrm{H}} 17$ differentiation, in vitro studies show that it requires multiple cytokines including TGF- $\beta$, IL-6, IL-21, IL-23, and IL-1 $\beta$ $[8,34-38]$. TGF- $\beta$ induces the expression of the retinoic acid-related orphan receptor ROR $\gamma \mathrm{t}$, which is the master transcription factor for the $\mathrm{T}_{\mathrm{H}} 17$ effector cell lineage [30]. However, TGF- $\beta$ alone is unable to initiate $\mathrm{T}_{\mathrm{H}} 17$ differentiation, as this cytokine also induces forkhead box p3 (Foxp3), which is a transcription factor essential for the differentiation of $\mathrm{T}_{\text {regs. }}$. Foxp3 would bind to ROR $\gamma \mathrm{t}$ and thereby inhibit ROR $\gamma$ t-directed IL-17 expression [39], and hence excess TGF- $\beta$ can inhibit expression and function of ROR $\gamma$ t. In the presence of proinflammatory cytokines such as IL- 6 or IL21 , this inhibitory effect would be relived, as these cytokines activate STAT3 and suppress the expression of Foxp3. As a result, the relative levels of ROR $\gamma \mathrm{t}$ are increased and $\mathrm{T}_{\mathrm{H}} 17$ cell differentiation is promoted. Once $\mathrm{T}_{\mathrm{H}} 17$ cells have developed, IL-23 is needed for stabilization and further expansion of these cells, as illustrated by studies with IL-23 receptordeficient mice [40].

\section{The Role of Microbiota in $T_{H} 17$ Immunity}

Since IL-23 is required for developing productive and sustained $\mathrm{T}_{\mathrm{H}} 17$ responses, the signals that induce the production of this cytokine might be critical in determining whether
$\mathrm{T}_{\mathrm{H}} 17$ cells dominated T cell response. Given that IL-23 is mainly produced by innate immune cells, including DCs and macrophages in the gut, it is not surprising to find that signals from commensal bacteria is necessary for induction of $\mathrm{T}_{\mathrm{H}} 17$ cells. This notion is supported by observation where $\mathrm{T}_{\mathrm{H}} 17$ cells were absent in the sterile gut of newborn mice but steadily increased from birth to post-weaning as symbiotic bacteria gradually colonized the intestine [41]. More importantly, it is not general bacterial colonization but the composition of bacteria that influence the makeup of the lamina propria $\mathrm{T}$ lymphocyte subsets. Ivanov et al. [32] has found that mice purchased from different vendors had shown marked differences in the number of $\mathrm{T}_{\mathrm{H}} 17$ cells in the gut. By sequencing microbiota of these animals, it was found that $\mathrm{T}_{\mathrm{H}} 17$ cell responses appear to be induced by specific classes of bacteria known as segmented filamentous bacteria (SFB), a Gram-positive bacteria belonging to the Firmicutes phylum and most closely related to the Clostridium genus [42]. Prominent $\mathrm{T}_{\mathrm{H}} 17$ responses may also be seen upon infection of pathogenic Mycobacterium [43], Klebsiella [44], and Citrobacter [36] or upon colonization with a complex microbial community [45]. Since multiple chronic liver diseases including HCC are often associated with intestinal dysbiosis and reduced species diversity [46-48], it seems that gut-derived microbial signals and intestinal immune network may be a factor to potentially reprogram systemic immune response towards a tumor-promoting direction.

The mechanisms of how intestinal bacteria prime DC for $\mathrm{T}_{\mathrm{H}} 17$ development is not yet fully understood, but it is likely to involve several microbial-derived molecules such as the toll-like receptor (TLR) ligands, adenosine $5^{\prime}$-triphosphate (ATP), and serum amyloid A (SAA) that result in IL-23 production. TLRs are a class of pattern-recognition receptors (PRRs) that play a key role in the innate immune system for recognizing various microbes and/or its products, collectively known as pathogen-associated molecular patterns (PAMPs) [49]. The nature of cytokines secreted by DC is dependent on PAMPs that DC encountered in the peripheral tissues during its immature phase. While stimulation of TLR4 by LPS gives both IL-23 and IL-12, stimulation of TLR2 by peptidoglycan generally induces large amounts of IL-23 from DC, though the quantity may vary depending on the structure of peptidoglycan [50]. TLR9 and TLR5 signaling may also be necessary, as illustrated by in vivo [51] and in vitro [52] studies, respectively. Apart from PAMPs, the binding of extracellular ATP could also elicit the release of IL-23 in addition to other IL-17 inducing proinflammatory cytokines such as IL- 6 and IL- $1 \beta$ from DC $[31,53,54]$ as a result of activating the membrane ion channel and $\mathrm{G}$ protein receptors such as ionotropic and metabotropic purinergic receptors $[55,56]$. The importance of the ATP signaling pathway was demonstrated in vitro, whereby the differentiation program of $\mathrm{T}_{\mathrm{H}} 17$ became severely inhibited upon addition of ATP degrading enzyme apyrase [31]. Commensal bacteria have been shown to generate copious amount of extracellular ATP [57] and thereby important in IL-23 production. Transient production of IL-23 by lamina propria DCs can also be induce by SAA, an acute phase protein found to be upregulated in the ileum by $\mathrm{T}_{\mathrm{H}} 17$ 


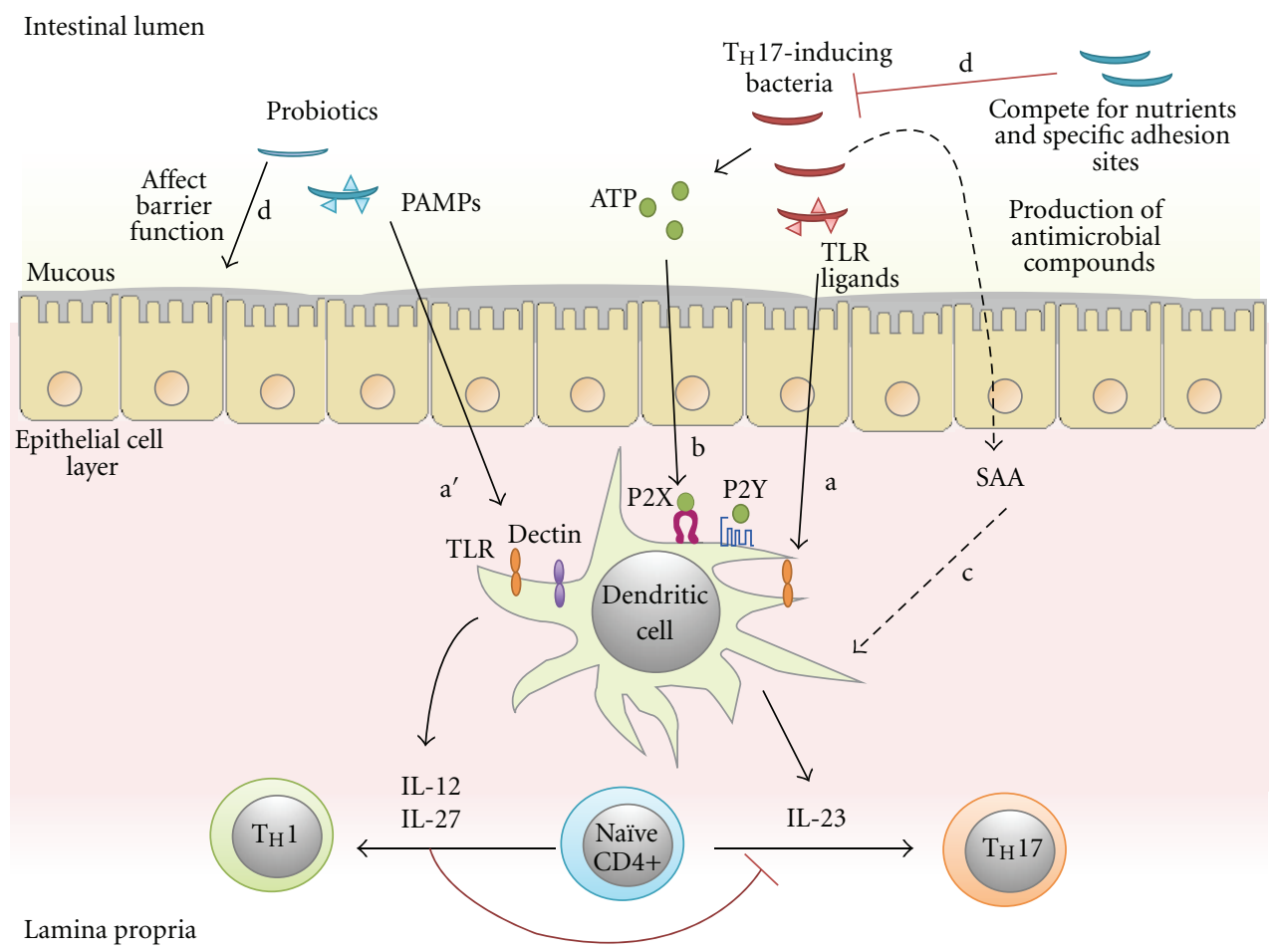

FIgURE 2: A simplified diagram showing the possible mechanisms of intestinal bacteria in influencing the polarization of $\mathrm{T}_{\mathrm{H}} 17$ cells in the lamina propria. Activation of dendritic cells by intestinal microbes results in secretion of proinflammatory cytokines such as IL-12, L-23, IL27. $\mathrm{T}_{\mathrm{H}} 17$-inducing bacteria may promote $\mathrm{T}_{\mathrm{H}} 17$ immunity via IL-23 induction, which may involve signaling mediated by the TLR ligands (a), extracellular ATP (b), and SAA (c). Meanwhile, some probiotic strains may skew immunity away from $\mathrm{T}_{\mathrm{H}} 17$ via IL-12 and IL-27 induction as a result of activating TLR and dectin receptors $\left(a^{\prime}\right)$. These cytokines can inhibit $T_{H} 17$ development while facilitate $T_{H} 1$ differentiation. Probiotic may also work by controlling the growth and colonization of $\mathrm{T}_{\mathrm{H}} 17$-inducing bacteria (d). IL: interleukin; P2X: ionotropic receptors; P2Y: metabotropic receptors; PAMPs: pathogen-associated molecular patterns; SAA: serum amyloid A; TLR: toll-like receptor.

inducing bacteria. However, the signaling pathways induced by SAA are currently unknown [58]. Collectively, these findings illustrate that microbiota played an important role in sustaining $\mathrm{T}_{\mathrm{H}} 17$ responses via IL-23 induction, which may involve signaling mediated by the TLR ligand, ATP, and SAA. This mechanism establishes a $\mathrm{T}_{\mathrm{H}} 17$ cell-inducing cytokine environment (Figure 2).

\section{Modulation of Extraintestinal $\mathbf{T}_{\mathrm{H}} 17$ Response by Commensal Bacteria}

Notably, the influence of commensal bacteria on the balance of $\mathrm{T}$ cell subsets is not only confined to the gut, but can also be extended to extraintestinal sites. This notion may be supported by several studies of autoimmune disease whose development is $\mathrm{T}_{\mathrm{H}} 17$-dependent. It was found that introduction of SFBs into the sterile gut of healthy mice was able to induce arthritis and encephalomyelitis [59, 60]. The aggravation of disease appeared to be the consequence of an increase in the number of $\mathrm{T}_{\mathrm{H}} 17$ cells that traffic out of the gut to the extraintestinal site, as Lee et al. [59] has revealed an increase in $\mathrm{T}_{\mathrm{H}} 17$ cell responses in spinal cords of SFB monocolonized mice in a model of encephalomyelitis. These findings may have significant implications for regulating systemic pathogenic $\mathrm{T}_{\mathrm{H}} 17$ by modulating the composition of intestinal bacteria, and probiotics have been suggested to exhibit this potential.

\section{Potential Immunomodulatory Capacity of Probiotics}

Probiotics are live microorganisms that confer health benefit to host when administered in adequate amounts [61]. The established probiotics are generally Lactobacillus and Bifidobacterium species, though Lactococcus, Enterococcus, and Streptococcus species, as well as some nonpathogenic strains of Escherichia coli that can also be found [62]. Administration of Lactobacillus and Bifidobacterium species orally has been shown to protect against the development of various $\mathrm{T}_{\mathrm{H}} 17$-mediated diseases [63-72], possibly via reprogramming $\mathrm{T}_{\mathrm{H}}$ cell response or by controlling growth of $\mathrm{T}_{\mathrm{H}} 17$-inducing bacteria. Due to strain or speciesspecific molecular characteristics of probiotic bacteria, the immunomodulatory effect exhibited may depend strongly on the choice of the probiotic strain.

Probiotic may prime DC for the development of other $\mathrm{T}_{\mathrm{H}}$ subsets. For example, activation of TLR or dectin receptors would trigger DC to produce IL-12p70, IL-23, 
or IL-27, which are important in skewing $\mathrm{T}_{\mathrm{H}} 1$ or $\mathrm{T}_{\mathrm{H}} 17$ immunity. While IL-23 sustains $\mathrm{T}_{\mathrm{H}} 17$ response, IL-12 and IL-27 drive $\mathrm{T}_{\mathrm{H}} 1$ differentiation by activating STAT1 and inducing the expression of $\mathrm{T}$ box transcription factor ( $\mathrm{T}$ bet), the key transcriptional regulator of $\mathrm{T}_{\mathrm{H}} 1$ cells [5]. IL27 and IFN- $\gamma$ derived from $\mathrm{T}_{\mathrm{H}} 1$ cells could downregulate ROR $\gamma \mathrm{t}$ in a STAT1-dependent manner and thereby dampen development of $\mathrm{T}_{\mathrm{H}} 17$ cells, whereas IL-17 from $\mathrm{T}_{\mathrm{H}} 17$ did not similarly suppress $\mathrm{T}_{\mathrm{H}} 1$ polarization [73]. IL-12 and IFN$\gamma$ would further increase T-bet expression in DC to drive $\mathrm{T}_{\mathrm{H}} 1$ differentiation [74]. Hence, probiotic strain that favors IL-12 and IL-27 is likely to skew immune response away from $\mathrm{T}_{\mathrm{H}} 17$ to $\mathrm{T}_{\mathrm{H}} 1$ (Figure 2). Several strains of Lactobacillus (e.g., L. acidophilus [75], L. gasseri [72], and L. rhamnosus [76]) and Bifidobacterium (e.g., B. lactis, B. breve and $B$. bifidum $[77,78]$ ) may possess this capacity. $\mathrm{T}_{\mathrm{H}} 1$ cytokines such as IL-12 and IFN- $\gamma$ are known to have potent antitumor immunity as they could activate cytotoxic T cells and NK cells to kill cancer cells. Deficiency of T-bet in DC leads to exaggerated TNF production and contributes to creating a chronic inflammatory state that modulates the composition of microbiota and eventually leads to cancer development $[79,80]$. Therefore, promoting $\mathrm{T}_{\mathrm{H}} 1$ differentiation by probiotics may possibly shift pathogenic $\mathrm{T}_{\mathrm{H}} 17$ inflammation to antitumor $\mathrm{T}_{\mathrm{H}} 1$ response.

Apart from regulating $\mathrm{T}$ cell polarization, probiotic may also work by controlling the growth of $\mathrm{T}_{\mathrm{H}} 17$-inducing bacteria such as SFB. Indeed, administration of L. plantarum almost completely depleted the SFB present in the ileum [81]. Although the underlying mechanisms have not yet been investigated in that study, it is tempting to speculate that probiotic may adversely affect SFB colonization and survival by competing for the use of nutrients and other external metabolites. In accordance to the highly reduced genome, SFBs lack a number of enzymes for basic metabolic pathways that are important for growth and survival, including biosynthesis of amino acids and cofactors. To compensate for these auxotrophies, SFB expressed a large array of transporters to acquire sugars, many cofactors, and nearly all amino acids and from the environment [82]. Lactobacillus may serve as a competitor for the uptake of amino acids, as genome sequencing has revealed a considerable degree of auxotrophy for amino acids in these bacteria. There may also be competition for the internalization and utilization of sugar, as Bifidobacterium and Lactobacillus situated in intestinal niche generally encode a large capacity for carbohydrate transport and metabolism [83-87]. Bifidobacterium have excellent carbohydrate sequestering capacity as they use a "docking station" to capture carbohydrate to their cell surface to avoid losing the molecules to nearby competitors [88-90]. In addition to amino acids and sugar utilization, the metabolism of some Lactobacillus strains, including L. paracasei or L. rhamnosus, could also lead to major changes to levels of a number of metabolites, including methylamines and short-chain fatty acids [91, 92]. Together, the metabolisms and activities of these commensal bacteria may create an unfavorable environment for functionality of SFB in vivo. Other strategies for probiotics to limit pathogenic bacterial growth may include production of antimicrobial compounds, competition for specific adhesion sites and maintaining intestinal tight junction [81], but these mechanisms will not be discussed here in detail. All these mechanisms may directly or indirectly change the composition and diversity of the intestinal microbiota and modulate DC-mediated immunity as mentioned above.

All in all, commensal bacteria of Bifidobacterium and Lactobacillus genera are associated with balancing $\mathrm{T}_{\mathrm{H}}$ response locally and systemically. Hence, establishing a balanced microbiota in favor of these protective probiotic bacteria may be a good strategy to maintain immune homeostasis via DC priming and that may possibly modulate tumorigenic proinflammatory milieu at sites distant from the gut.

\section{Conclusion}

In conclusion, $\mathrm{T}_{\mathrm{H}} 17$ has recently been found in HCC tumor and its presence has been linked to disease progression, possibly involving angiogenesis. Gut $\mathrm{T}_{\mathrm{H}} 17$ seems to be a potential source for tumor-associated $\mathrm{T}_{\mathrm{H}} 17$, where it could be homed to the tumor environment via CCR6/CCL20 axis and expand locally. Commensal bacteria are necessary for development of gut $\mathrm{T}_{\mathrm{H}} 17$ by IL-23 induction in DC. Probiotics may affect cytokine profile of DC by activating different PRRs and controlling the growth of some potent $\mathrm{T}_{\mathrm{H}} 17$ inducers such as SFB. This potential linkage of HCC environment, $\mathrm{T}_{\mathrm{H}} 17$ cells, and microbiota may implicate for novel targets for therapeutic intervention in HCC progression.

\section{References}

[1] H. B. El-Serag and K. L. Rudolph, "Hepatocellular carcinoma: epidemiology and molecular carcinogenesis," Gastroenterology, vol. 132, no. 7, pp. 2557-2576, 2007.

[2] M. M. Mueller and N. E. Fusenig, "Friends or foes-bipolar effects of the tumour stroma in cancer," Nature Reviews Cancer, vol. 4, no. 11, pp. 839-849, 2004.

[3] Y. Wu and L. Zheng, "Dynamic education of macrophages in different areas of human tumors," Cancer Microenviron, vol. 5, no. 3, pp. 195-201, 2012.

[4] F. Ahmed, J. C. Steele, J. M. J. Herbert, N. M. Steven, and R. Bicknell, "Tumor stroma as a target in cancer," Current Cancer Drug Targets, vol. 8, no. 6, pp. 447-453, 2008.

[5] T. Korn, E. Bettelli, M. Oukka, and V. K. Kuchroo, "IL-17 and Th17 cells," Annual Review of Immunology, vol. 27, pp. 485517, 2009.

[6] L. A. Zenewicz and R. A. Flavell, "Recent advances in IL-22 biology," International Immunology, vol. 23, no. 3, pp. 159163, 2011.

[7] D. M. Kuang, C. Peng, Q. Zhao, Y. Wu, M. S. Chen, and L. Zheng, "Activated monocytes in peritumoral stroma of hepatocellular carcinoma promote expansion of memory $\mathrm{T}$ helper 17 cells," Hepatology, vol. 51, no. 1, pp. 154-164, 2010.

[8] C. T. Weaver, R. D. Hatton, P. R. Mangan, and L. E. Harrington, "IL-17 family cytokines and the expanding diversity of effector T cell lineages," Annual Review of Immunology, vol. 25, pp. 821-852, 2007.

[9] D. M. Kuang, C. Peng, Q. Zhao et al., "Tumor-activated monocytes promote expansion of IL-17-producing $\mathrm{CD}^{+}$ $\mathrm{T}$ cells in hepatocellular carcinoma patients," Journal of Immunology, vol. 185, no. 3, pp. 1544-1549, 2010. 
[10] R. Jiang, Z. Tan, L. Deng et al., "Interleukin-22 promotes human hepatocellular carcinoma by activation of STAT3," Hepatology, vol. 54, no. 3, pp. 900-909, 2011.

[11] L. A. Zenewicz and R. A. Flavell, "IL-22 and inflammation: Leukin' through a glass onion," European Journal of Immunology, vol. 38, no. 12, pp. 3265-3268, 2008.

[12] J. P. Zhang, J. Yan, J. Xu et al., "Increased intratumoral IL-17producing cells correlate with poor survival in hepatocellular carcinoma patients," Journal of Hepatology, vol. 50, no. 5, pp. 980-989, 2009.

[13] F. Zhao, B. Hoechst, J. Gamrekelashvili et al., "Human CCR4 ${ }^{+}$ CCR6 ${ }^{+}$Th17 cells suppress autologous CD8 ${ }^{+}$T cell responses," The Journal of Immunology, vol. 188, no. 12, pp. 6055-6062, 2012.

[14] W. W. Wang, Z. M. Wang, Y. Y. Liu, Y. H. Qin, and Q. Shen, "Increased level of Th17 cells in peripheral blood correlates with the development of hepatocellular carcinoma," Zhonghua Zhong Liu Za Zhi, vol. 32, no. 10, pp. 757-761, 2010.

[15] B. Zhang, G. Rong, H. Wei et al., "The prevalence of Th17 cells in patients with gastric cancer," Biochemical and Biophysical Research Communications, vol. 374, no. 3, pp. 533-537, 2008.

[16] F. Fossiez, O. Djossou, P. Chomarat et al., "T cell interleukin17 induces stromal cells to produce proinflammatory and hematopoietic cytokines," Journal of Experimental Medicine, vol. 183, no. 6, pp. 2593-2603, 1996.

[17] Z. Yao, S. L. Painter, W. C. Fanslow et al., "Human IL-17: a novel cytokine derived from T cells," Journal of Immunology, vol. 155, no. 12, pp. 5483-5486, 1995.

[18] M. Numasaki, J. I. Fukushi, M. Ono et al., "Interleukin-17 promotes angiogenesis and tumor growth," Blood, vol. 101, no. 7, pp. 2620-2627, 2003.

[19] M. Numasaki, M. T. Lotze, and H. Sasaki, "Interleukin17 augments tumor necrosis factor- $\alpha$-induced elaboration of proangiogenic factors from fibroblasts," Immunology Letters, vol. 93, no. 1, pp. 39-43, 2004.

[20] J. H. Niess, F. Leithäuser, G. Adler, and J. Reimann, "Commensal gut flora drives the expansion of proinflammatory CD4 T cells in the colonic lamina propria under normal and inflammatory conditions," Journal of Immunology, vol. 180, no. 1, pp. 559-568, 2008.

[21] D. V. Jovanovic, J. A. Di Battista, J. Martel-Pelletier et al., "IL17 stimulates the production and expression of proinflammatory cytokines, IL- $\beta$ and TNF- $\alpha$, by human macrophages," Journal of Immunology, vol. 160, no. 7, pp. 3513-3521, 1998.

[22] M. Numasaki, M. Watanabe, T. Suzuki et al., "IL-17 enhances the net angiogenic activity and in vivo growth of human non-small cell lung cancer in SCID mice through promoting CXCR-2-dependent angiogenesis," Journal of Immunology, vol. 175, no. 9, pp. 6177-6189, 2005.

[23] W. Zhang, Y. Chen, H. Wei et al., "Antiapoptotic activity of autocrine interleukin-22 and therapeutic effects of interleukin-22-small interfering RNA on human lung cancer xenografts," Clinical Cancer Research, vol. 14, no. 20, pp. 64326439, 2008.

[24] H. Yu and R. Jove, "The stats of cancer-new molecular targets come of age," Nature Reviews Cancer, vol. 4, no. 2, pp. 97-105, 2004.

[25] S. Radaeva, R. Sun, H. N. Pan, F. Hong, and B. Gao, "Interleukin 22 (IL-22) plays a protective role in T cellmediated murine hepatitis: IL-22 is a survival factor for hepatocytes via STAT3 activation," Hepatology, vol. 39, no. 5, pp. 1332-1342, 2004.

[26] L. Curd, S. Favors, and R. Gregg, "Pro-tumour activity of interleukin-22 in HPAFII human pancreatic cancer cells,"
Clinical \& Experimental Immunology, vol. 168, no. 2, pp. 192199, 2012.

[27] E. Volpe, N. Servant, R. Zollinger et al., "A critical function for transforming growth factor- $\beta$, interleukin 23 and proinflammatory cytokines in driving and modulating human $\mathrm{TH}-$ 17 responses," Nature Immunology, vol. 9, no. 6, pp. 650-657, 2008.

[28] N. Manel, D. Unutmaz, and D. R. Littman, "The differentiation of human TH-17 cells requires transforming growth factor- $\beta$ and induction of the nuclear receptor ROR $\gamma \mathrm{t}$," Nature Immunology, vol. 9, no. 6, pp. 641-649, 2008.

[29] K. Nistala, S. Adams, H. Cambrook et al., "Th17 plasticity in human autoimmune arthritis is driven by the inflammatory environment," Proceedings of the National Academy of Sciences of the United States of America, vol. 107, no. 33, pp. 1475114756, 2010.

[30] I. I. Ivanov, B. S. McKenzie, L. Zhou et al., "The orphan nuclear receptor ROR $\gamma \mathrm{t}$ directs the differentiation program of proinflammatory IL-17+ T helper cells," Cell, vol. 126, no. 6, pp. 1121-1133, 2006.

[31] K. Atarashi, J. Nishimura, T. Shima et al., "ATP drives lamina propria TH17 cell differentiation," Nature, vol. 455, no. 7214, pp. 808-812, 2008.

[32] I. I. Ivanov, R. D. L. Frutos, N. Manel et al., "Specific microbiota direct the differentiation of IL-17-producing Thelper cells in the mucosa of the small intestine," Cell Host and Microbe, vol. 4, no. 4, pp. 337-349, 2008.

[33] E. K. Deenick and S. G. Tangye, "Autoimmunity: IL-21: a new player in Th17-cell differentiation," Immunology and Cell Biology, vol. 85, no. 7, pp. 503-505, 2007.

[34] E. Bettelli, T. Korn, M. Oukka, and V. K. Kuchroo, "Induction and effector functions of TH17 cells," Nature, vol. 453, no. 7198, pp. 1051-1057, 2008.

[35] M. Veldhoen, R. J. Hocking, C. J. Atkins, R. M. Locksley, and B. Stockinger, "TGF $\beta$ in the context of an inflammatory cytokine milieu supports de novo differentiation of IL-17-producing T cells," Immunity, vol. 24, no. 2, pp. 179-189, 2006.

[36] P. R. Mangan, L. E. Harrington, D. B. O'Quinn et al., "Transforming growth factor- $\beta$ induces development of the T H17 lineage," Nature, vol. 441, no. 7090, pp. 231-234, 2006.

[37] E. Bettelli, Y. Carrier, W. Gao et al., "Reciprocal developmental pathways for the generation of pathogenic effector TH17 and regulatory T cells," Nature, vol. 441, no. 7090, pp. 235-238, 2006.

[38] Y. Chung, S. H. Chang, G. J. Martinez et al., "Critical regulation of early Th17 cell differentiation by interleukin-1 signaling," Immunity, vol. 30, no. 4, pp. 576-587, 2009.

[39] L. Zhou, J. E. Lopes, M. M. W. Chong et al., "TGF-betainduced Foxp3 inhibits TH17 cell differentiation by antagonizing RORgammat function," Nature, vol. 453, no. 7192, pp. 236-240, 2008.

[40] K. M. Murphy and S. L. Reiner, "The lineage decisions of helper T cells," Nature Reviews Immunology, vol. 2, no. 12, pp. 933-944, 2002.

[41] C. Palmer, E. M. Bik, D. B. DiGiulio, D. A. Relman, and P. O. Brown, "Development of the human infant intestinal microbiota,” PLoS Biology, vol. 5, no. 7, article e177, 2007.

[42] J. Snel, P. P. Heinen, H. J. Blok et al., "Comparison of $16 \mathrm{~S}$ rRNA sequences of segmented filamentous bacteria isolated from mice, rats, and chickens and proposal of 'Candidatus Arthromitus', International Journal of Systematic Bacteriology, vol. 45, no. 4, pp. 780-782, 1995.

[43] A. Cruz, S. A. Khader, E. Torrado et al., "Cutting edge: IFN$\gamma$ regulates the induction and expansion of IL-17-producing 
CD4 T cells during mycobacterial infection," Journal of Immunology, vol. 177, no. 3, pp. 1416-1420, 2006.

[44] K. I. Happel, M. Zheng, E. Young et al., "Cutting edge: roles of toll-like receptor 4 and IL-23 in IL-17 expression in response to Klebsiella pneumoniae infection," Journal of Immunology, vol. 170, no. 9, pp. 4432-4436, 2003.

[45] J. H. Niess, F. Leithäuser, G. Adler, and J. Reimann, "Commensal gut flora drives the expansion of proinflammatory CD4 T cells in the colonic lamina propria under normal and inflammatory conditions," Journal of Immunology, vol. 180, no. 1, pp. 559-568, 2008.

[46] D. H. Dapito, A. Mencin, G. Gwak et al., "Promotion of hepatocellular carcinoma by the intestinal microbiota and TLR4," Cancer Cell, vol. 21, no. 4, pp. 504-516, 2012.

[47] J. G. Fox, Y. Feng, E. J. Theve et al., "Gut microbes define liver cancer risk in mice exposed to chemical and viral transgenic hepatocarcinogens," Gut, vol. 59, no. 1, pp. 88-97, 2010.

[48] C. Cesaro, A. Tiso, A. Del Prete et al., "Gut microbiota and probiotics in chronic liver diseases," Digestive and Liver Disease, vol. 43, no. 6, pp. 431-438, 2011.

[49] H. H. Smits, A. Engering, D. Van Der Kleij et al., "Selective probiotic bacteria induce IL-10-producing regulatory $\mathrm{T}$ cells in vitro by modulating dendritic cell function through dendritic cell-specific intercellular adhesion molecule 3-grabbing nonintegrin," Journal of Allergy and Clinical Immunology, vol. 115, no. 6, pp. 1260-1267, 2005.

[50] F. Re and J. L. Strominger, "Toll-like receptor 2 (TLR2) and TLR4 differentially activate human dendritic cells," Journal of Biological Chemistry, vol. 276, no. 40, pp. 37692-37699, 2001.

[51] J. A. Hall, N. Bouladoux, C. M. Sun et al., "Commensal DNA limits regulatory $\mathrm{T}$ cell conversion and is a natural adjuvant of intestinal immune responses," Immunity, vol. 29, no. 4, pp. 637-649, 2008.

[52] S. Uematsu, K. Fujimoto, M. H. Jang et al., "Regulation of humoral and cellular gut immunity by lamina propria dendritic cells expressing Toll-like receptor 5," Nature Immunology, vol. 9, no. 7, pp. 769-776, 2008.

[53] J. Chow and S. K. Mazmanian, "Getting the bugs out of the immune system: do bacterial microbiota "fix" intestinal T cell responses?” Cell Host and Microbe, vol. 5, no. 1, pp. 8-12, 2009.

[54] M. Schnurr, T. Toy, A. Shin, M. Wagner, J. Cebon, and E. Maraskovsky, "Extracellular nucleotide signaling by P2 receptors inhibits IL-12 and enhances IL-23 expression in human dendritic cells: a novel role for the cAMP pathway," Blood, vol. 105, no. 4, pp. 1582-1589, 2005.

[55] B. S. Khakh and R. A. North, "P2X receptors as cell-surface ATP sensors in health and disease," Nature, vol. 442, no. 7102, pp. 527-532, 2006.

[56] K. Atarashi, T. Tanoue, and K. Honda, "Induction of lamina propria Th17 cells by intestinal commensal bacteria," Vaccine, vol. 28, no. 50, pp. 8036-8038, 2010.

[57] E. P. Ivanova, Y. V. Alexeeva, D. K. Pham, J. P. Wright, and D. V. Nicolau, "ATP level variations in heterotrophic bacteria during attachment on hydrophilic and hydrophobic surfaces," International Microbiology, vol. 9, no. 1, pp. 37-46, 2006.

[58] I. I. Ivanov, K. Atarashi, N. Manel et al., "Induction of intestinal Th17 cells by segmented filamentous bacteria," Cell, vol. 139, no. 3, pp. 485-498, 2009.

[59] Y. K. Lee, J. S. Menezes, Y. Umesaki, and S. K. Mazmanian, "Proinflammatory T-cell responses to gut microbiota promote experimental autoimmune encephalomyelitis," Proceedings of the National Academy of Sciences of the United States of America, vol. 108, supplement 1, pp. 4615-4622, 2011.
[60] H. J. Wu, I. I. Ivanov, J. Darce et al., "Gut-residing segmented filamentous bacteria drive autoimmune arthritis via $\mathrm{T}$ helper 17 cells," Immunity, vol. 32, no. 6, pp. 815-827, 2010.

[61] G. Reid, M. E. Sanders, H. R. Gaskins et al., "New scientific paradigms for probiotics and prebiotics," Journal of Clinical Gastroenterology, vol. 37, no. 2, pp. 105-118, 2003.

[62] A. T. Borchers, C. Selmi, F. J. Meyers, C. L. Keen, and M. E. Gershwin, "Probiotics and immunity," Journal of Gastroenterology, vol. 44, no. 1, pp. 26-46, 2009.

[63] T. Matsuzaki, Y. Nagata, S. Kado et al., "Prevention of onset in an insulin-dependent diabetes mellitus model, NOD mice, by oral feeding of Lactobacillus casei," APMIS, vol. 105, no. 8, pp. 643-649, 1997.

[64] F. Calcinaro, S. Dionisi, M. Marinaro et al., "Oral probiotic administration induces interleukin-10 production and prevents spontaneous autoimmune diabetes in the non-obese diabetic mouse," Diabetologia, vol. 48, no. 8, pp. 1565-1575, 2005.

[65] S. Lavasani, B. Dzhambazov, M. Nouri et al., "A novel probiotic mixture exerts a therapeutic effect on experimental autoimmune encephalomyelitis mediated by IL-10 producing regulatory T cells," PLoS One, vol. 5, no. 2, article e9009, 2010.

[66] I. Kato, K. Endo-Tanaka, and T. Yokokura, "Suppressive effects of the oral administration of Lactobacillus casei on type ii collagen-induced arthritis in DBA/1 mice," Life Sciences, vol. 63, no. 8, pp. 635-644, 1998.

[67] E. Baharav, F. Mor, M. Halpern, and A. Weinberger, "Lactobacillus GG bacteria ameliorate arthritis in Lewis rats," Journal of Nutrition, vol. 134, no. 8, pp. 1964-1969, 2004.

[68] J. S. So, H. K. Kwon, C. G. Lee et al., "Lactobacillus casei suppresses experimental arthritis by down-regulating T helper 1 effector functions," Molecular Immunology, vol. 45, no. 9, pp. 2690-2699, 2008.

[69] C. Di Giacinto, M. Marinaro, M. Sanchez, W. Strober, and M. Boirivant, "Probiotics ameliorate recurrent Th1-mediated murine colitis by inducing IL-10 and IL-10-dependent TGF- $\beta$ bearing regulatory cells," Journal of Immunology, vol. 174, no. 6, pp. 3237-3246, 2005.

[70] C. O’Mahony, P. Scully, D. O’Mahony et al., “Commensalinduced regulatory $\mathrm{T}$ cells mediate protection against pathogen-stimulated NF- $\kappa$ B activation," PLoS Pathogens, vol. 4, no. 8, Article ID e1000112, 2008.

[71] M. Livingston, D. Loach, M. Wilson, G. W. Tannock, and M. Baird, "Gut commensal Lactobacillus reuteri 100-23 stimulates an immunoregulatory response," Immunology and Cell Biology, vol. 88, no. 1, pp. 99-102, 2010.

[72] R. L. Jan, K. C. Yeh, M. H. Hsieh et al., "Lactobacillus gasseri suppresses Th17 pro-inflammatory response and attenuates allergen-induced airway inflammation in a mouse model of allergic asthma," British Journal of Nutrition, vol. 108, no. 1, pp. 130-139, 2012.

[73] L. Zhou, M. M. W. Chong, and D. R. Littman, "Plasticity of $\mathrm{CD}^{+}{ }^{+} \mathrm{T}$ cell lineage differentiation," Immunity, vol. 30, no. 5, pp. 646-655, 2009.

[74] V. Lazarevic and L. H. Glimcher, "T-bet in disease," Nature Immunology, vol. 12, no. 7, pp. 597-606, 2011.

[75] C. C. Chen, C. H. Chiu, T. Y. Lin, H. N. Shi, and W. A. Walker, "Effect of probiotics Lactobacillus acidophilus on Citrobacter rodentium colitis: the role of dendritic cells," Pediatric Research, vol. 65, no. 2, pp. 169-175, 2009.

[76] V. Veckman, M. Miettinen, J. Pirhonen, J. Sirén, S. Matikainen, and I. Julkunen, "Streptococcus pyogenes and Lactobacillus rhamnosus differentially induce maturation and production 
of Th1-type cytokines and chemokines in human monocytederived dendritic cells," Journal of Leukocyte Biology, vol. 75, no. 5, pp. 764-771, 2004.

[77] P. López, I. González-Rodríguez, M. Gueimonde et al., "Immune response to Bifidobacterium bifidum strains support Treg/Th17 plasticity," PLoS One, vol. 6, no. 9, article e24776, 2011.

[78] S. G. Jeon, H. Kayama, Y. Ueda et al., "Probiotic Bifidobacterium breve induces IL-10-producing $\operatorname{Tr} 1$ cells in the colon," PLOS Pathogens, vol. 8, no. 5, article e1002714, 2012.

[79] M. J. Molloy, N. Bouladoux, and Y. Belkaid, Intestinal Microbiota: Shaping Local and Systemic Immune Responses, Elsevier, 2011.

[80] W. S. Garrett, S. Punit, C. A. Gallini et al., "Colitis-associated colorectal cancer driven by T-bet deficiency in dendritic cells," Cancer Cell, vol. 16, no. 3, pp. 208-219, 2009.

[81] S. Fuentes, M. Egert, M. Jimenez-Valera, M. MonteolivaSanchez, A. Ruiz-Bravo, and H. Smidt, "A strain of Lactobacillus plantarum affects segmented filamentous bacteria in the intestine of immunosuppressed mice," FEMS Microbiology Ecology, vol. 63, no. 1, pp. 65-72, 2008.

[82] T. Prakash, K. Oshima, H. Morita et al., "Complete genome sequences of rat and mouse segmented filamentous bacteria, a potent inducer of th17 cell differentiation," Cell Host \& Microbe, vol. 10, no. 3, pp. 273-284, 2011.

[83] M. Kleerebezem and E. E. Vaughan, "Probiotic and gut lactobacilli and bifidobacteria: molecular approaches to study diversity and activity," Annual Review of Microbiology, vol. 63, pp. 269-290, 2009.

[84] J. F. Kim, H. Jeong, D. S. Yu et al., "Genome sequence of the probiotic bacterium Bifidobacterium animalis subsp. lactis AD011," Journal of Bacteriology, vol. 191, no. 2, pp. 678-679, 2009.

[85] S. M. Ryan, G. F. Fitzgerald, and D. Van Sinderen, "Transcriptional regulation and characterization of a novel $\beta$-fructofuranosidase-encoding gene from Bifidobacterium breve UCC2003," Applied and Environmental Microbiology, vol. 71, no. 7, pp. 3475-3482, 2005.

[86] M. A. Schell, M. Karmirantzou, B. Snel et al., "The genome sequence of Bifidobacterium longum reflects its adaptation to the human gastrointestinal tract," Proceedings of the National Academy of Sciences of the United States of America, vol. 99, no. 22, pp. 14422-14427, 2002.

[87] D. A. Sela, J. Chapman, A. Adeuya et al., "The genome sequence of Bifidobacterium longum subsp. infantis reveals adaptations for milk utilization within the infant microbiome," Proceedings of the National Academy of Sciences of the United States of America, vol. 105, no. 48, pp. 18964-18969, 2008.

[88] L. A. M. Van Den Broek, S. W. A. Hinz, G. Beldman, J. P. Vincken, and A. G. J. Voragen, "Bifidobacterium carbohydrases-their role in breakdown and synthesis of (potential) prebiotics," Molecular Nutrition and Food Research, vol. 52, no. 1, pp. 146-163, 2008.

[89] S. W. A. Hinz, R. Verhoef, H. A. Schols, J. P. Vincken, and A. G. J. Voragen, "Type I arabinogalactan contains $\beta$-D-Galp- $(1 \rightarrow$ 3)- $\beta$-D-Galp structural elements," Carbohydrate Research, vol. 340, no. 13, pp. 2135-2143, 2005.

[90] M. Ventura, S. O’Flaherty, M. J. Claesson et al., "Genomescale analyses of health-promoting bacteria: probiogenomics," Nature Reviews Microbiology, vol. 7, no. 1, pp. 61-71, 2009.

[91] F. P. J. Martin, Y. Wang, N. Sprenger et al., "Probiotic modulation of symbiotic gut microbial-host metabolic interactions in a humanized microbiome mouse model," Molecular Systems Biology, vol. 4, article 157, 2008.

[92] M. Ventura, S. O’Flaherty, M. J. Claesson et al., "Genomescale analyses of health-promoting bacteria: probiogenomics," Nature Reviews Microbiology, vol. 7, no. 1, pp. 61-71, 2009. 


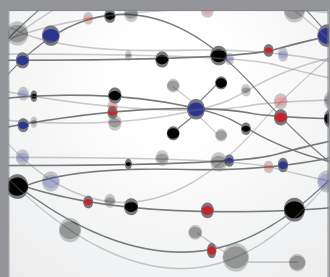

The Scientific World Journal
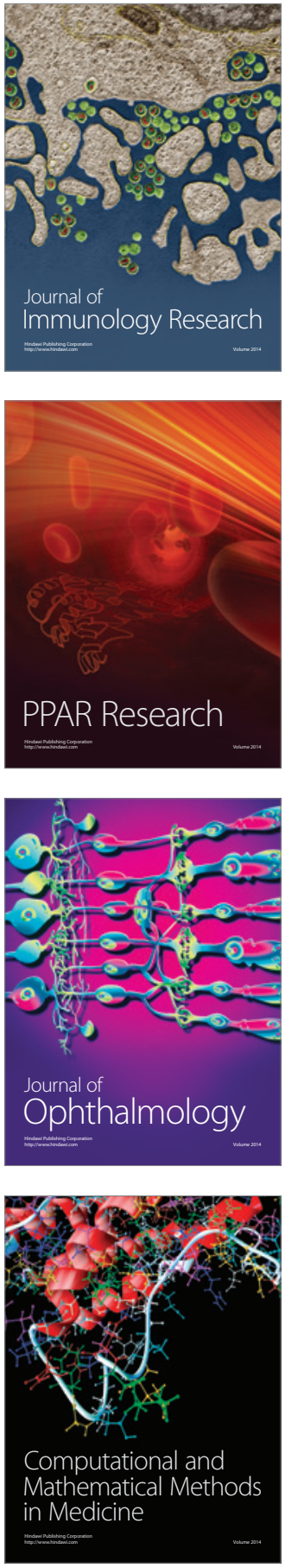

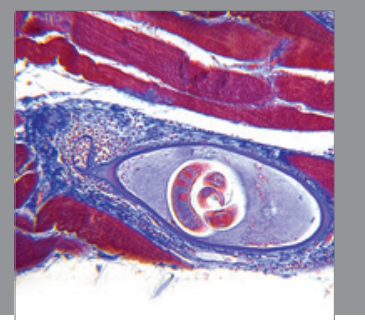

Gastroenterology

Research and Practice
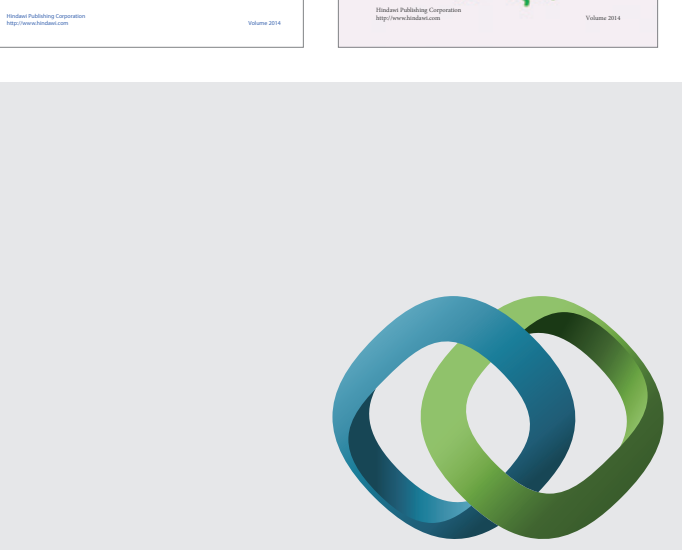

\section{Hindawi}

Submit your manuscripts at

http://www.hindawi.com
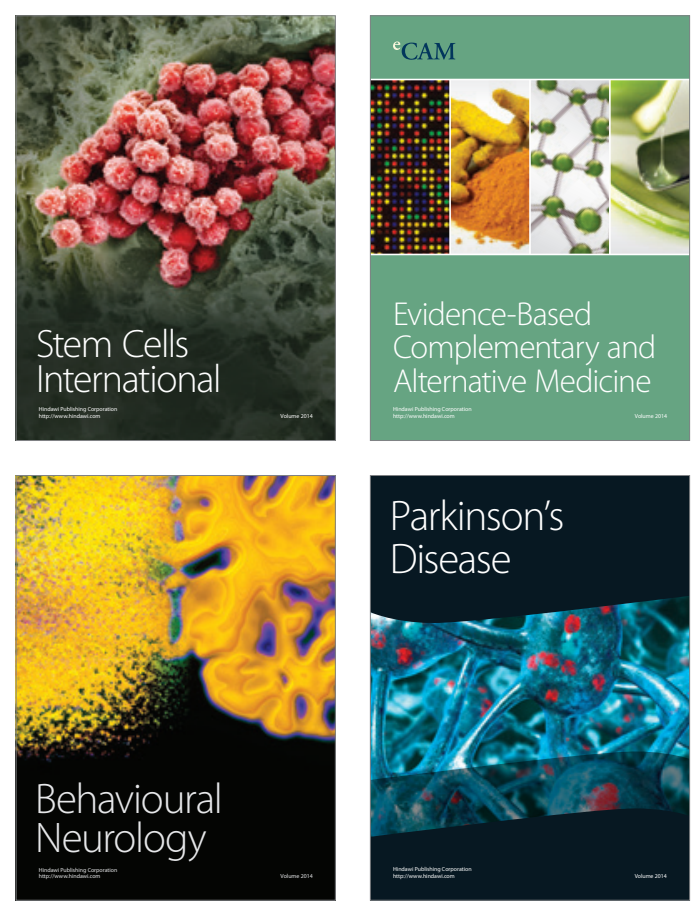

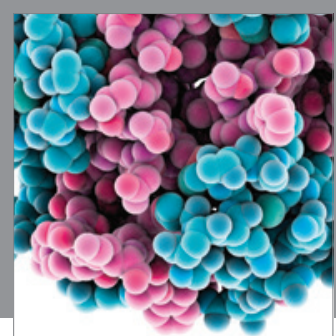

Journal of
Diabetes Research

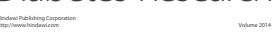

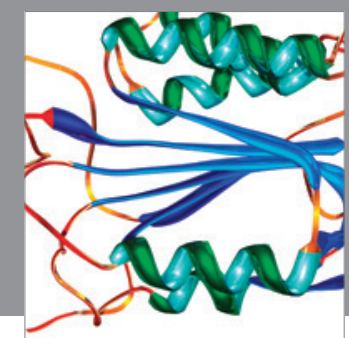

Disease Markers
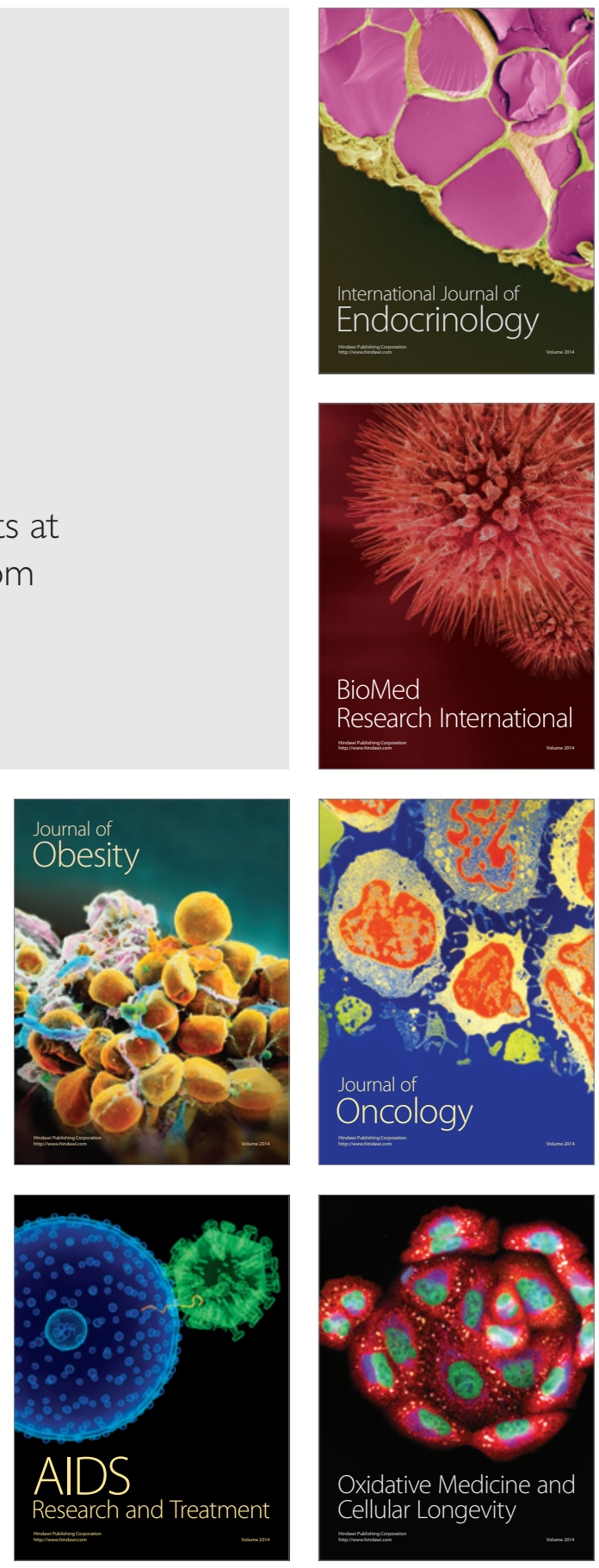